\title{
Solvent Uptake of Liquid Rubber Toughened Epoxy/Clay
} Nanocomposites

\author{
P. P. VIJAYAN \\ School of Chemical Sciences, Mahatma Gandhi University, Kottayam 686 560, India \\ Center for Advanced Materials, Qatar University, P.O. Box 2713, Doha-Qatar
}

\section{G. HARIKRISHNAN}

Department of Chemistry, National Institute of Technology, Calicut, Kozhikode 673 601, India

\section{PUGLIA}

Materials Engineering Centre, University of Perugia, Department of Civil and Environmental Engineering, UdR INSTM, Strada di Pentima 4 05100, Terni, Italy

\section{P. P. VIJAYAN \\ Department of Physics, St. Berchmans College, Changanacherry, Kottayam 686 001, India}

\section{J. M. KENNY}

Materials Engineering Centre, University of Perugia, Department of Civil and Environmental Engineering, UdR INSTM, Strada di Pentima 4 05100, Terni, Italy

\section{S. THOMAS}

School of Chemical Sciences, Mahatma Gandhi University, Kottayam 686 560, India

Centre for Nanoscience and Nanotechnology, Mahatma Gandhi University, Kottayam 686560, India

Correspondence to: D. Puglia; e-mail: debora.puglia@unipg.it.

Received: July 18, 2014

Accepted: February 17, 2015

\begin{abstract}
Carboxyl-terminated poly (butadiene-co-acrylonitrile) (CTBN) liquid rubber toughened epoxy (epoxy/CTBN blend) and CTBN-toughened epoxy/clay nanocomposites (epoxy/clay/CTBN nanocomposites) were prepared, and solvent (acetone) uptake was studied as a function of CTBN content. It was found that in both epoxy/CTBN blend and epoxy/clay/CTBN nanocomposites, the diffusion coefficient initially increased with an increase in CTBN content, with a maximum value registered for the systems containing $15 \mathrm{phr}$ of CTBN. With a further increase of CTBN, the diffusion coefficient was found to decrease. The variation of solvent uptake with CTBN content depends on both the amount of dissolved rubber in the epoxy phase and the phase morphology associated with each composition. The high acetone uptake in 15 and 20 phr CTBN-loaded system was found to be reduced dramatically by the incorporation of $3 \mathrm{phr}$ nanoclay. Owing to the presence of high aspect ratio clay platelets, the diffusion of acetone undergoes a more tortuous path in epoxy/clay/CTBN nanocomposites than in epoxy/CTBN blends. A diffusion mechanism correlated to composition for epoxy/CTBN blend and epoxy/clay/CTBN nanocomposites was proposed. ๑ 2015 Wiley Periodicals, Inc. Adv Polym Technol 2016, 35, 21531; View this article online at wileyonlinelibrary.com. DOI 10.1002/adv.21531
\end{abstract}

KEY WORDS: Diffusion, Morphology, Nanocomposites, Rubber, Transport properties

\section{Introduction}

Contract grant sponsor: Council of Scientific \& Industrial Research, New Delhi, India.
$\mathbf{E}$ poxy resins have excellent processability, which made this polymer a widely acceptable industrial engineering 
polymer. The research in epoxy resin and their modification with thermoplastics, ${ }^{1,2}$ liquid rubber, ${ }^{3,4}$ nanoclay, ${ }^{5,6}$ nanosilica,, 8 and so on help to design multicomponent epoxy with desired properties. The evaluation of solvent transport properties of epoxy, if we referred especially to structural adhesives and protective coating applications, is highly significant. The diffusion of solvents as a function of chemical nature of the cured epoxy resin and the chemical structure of the solvent were studied by Kaplan. ${ }^{9}$ The role of different nanofillers in epoxy matrix as a barrier to organic solvents and water has also been investigated by researchers. The addition of nanosized fillers such as boron nitride, synthetic diamond, and silicon nitride $\left(\mathrm{Si}_{3} \mathrm{~N}_{4}\right)$ into epoxy was found to improve the moisture resistance of epoxy composite thin films. ${ }^{10}$ Prolongo et al. ${ }^{11}$ reported that the maximum water content absorbed by the epoxy matrix was decreased significantly with the incorporation of carbon nanotubes and nanofibers. The effectiveness of nanoclay platelets in reducing the diffusion of acetone in the exfoliated aerospace epoxy-clay nanocomposite was reported by Chen et al. ${ }^{12}$ Moreover, Liu et al. ${ }^{13}$ observed a significant reduction in the water diffusivity and the maximum water uptake of the aircraft-grade epoxy resin with the addition of the nanoclay. Abacha et al. ${ }^{14}$ found that the nanoclay layers significantly improve the barrier properties of epoxy matrix against corrosive acid (sulfuric acid). The role of nanoclay on reducing water uptake of reinforced epoxy composites was also evident in epoxy systems containing natural fiber. ${ }^{15,16}$ The incorporation of low molecular weight liquid rubbers into epoxy matrix with the aim of reducing its inherent brittleness is a common practice in adhesive and coating industry. ${ }^{17,18}$ It has been demonstrated that the performance of liquid rubber toughened epoxy could be improved by the incorporation of nanoclay. ${ }^{19}$ Considering the importance of such a hybrid epoxy system, in this current study, we aim to investigate the solvent (acetone) uptake behavior of liquid rubber toughened epoxy/clay nanocomposites.

In the present paper, we studied the diffusion behavior of acetone in carboxyl-terminated poly (butadiene-co-acrylonitrile) (CTBN) liquid rubber toughened epoxy/clay nanocomposites as a function of CTBN content. Moreover, a comparison with diffusion behavior of CTBN-toughened epoxy was done. A correlation of solvent uptake behavior in epoxy/CTBN blend and epoxy/clay/CTBN nanocomposites with the amount of dissolved rubber in epoxy phase and phase morphology of each composition was considered.

\section{Experimental}

\section{MATERIALS}

The epoxy resin used was DGEBA (Diglycidyl ether of bisphenol A) GY250 grade, with an epoxide equivalent weight of approximately $183 \mathrm{~g}$ / equiv, nadic methyl anhydride (HY906), and benzyl dimethyl amine (DY062), all provided by Huntsman Advanced Materials (Basel, Switzerland), were selected as a curing agent and accelerator, respectively. Nanomer I.28E (Nanocor Inc., Hoffman Estates, IL, USA), specifically designed for epoxy anhydride resin systems, was used as an organically modified nanoclay. Carboxyl-terminated poly (butadiene-co-acrylonitrile) $(\mathrm{CTBN} 1300 \times 8)$, provided by
Hypro Reactive Liquid Polymers (CVC Thermoset Specialties, Moorestown, NJ), was selected as a reactive liquid rubber.

\section{PREPARATION OF NANOCOMPOSITES}

The unmodified epoxy was prepared by mixing GY250 resin with nadic methyl anhydride and benzyl dimethyl amine in the ratio 100:80:1 and poured into a preheated mold for curing. Epoxy/CTBN binary blends were prepared by mixing 10-20 phr (per hundred resin) of CTBN to the epoxy prepolymer for $10 \mathrm{~min}$. Hardener and catalyst were then added and mixed well for $10 \mathrm{~min}$. The mixture was then poured into a preheated mold and cured.

For the preparation of epoxy/clay nanocomposite, 3 phr nanoclay was mixed with epoxy using an IKA magnetic stirrer (RH basic 2 IKAMAG, IKA, Staufen, Germany) for $30 \mathrm{~min}$. It was then mixed using an IKA Ultra Turrax T25 (IKA, Staufen, Germany) homogenizer at 20,000 rpm for $10 \mathrm{~min}$. During the process, the temperature was maintained low by using an ice bath. Degassing of the mixture was carried out in a vacuum chamber for $2 \mathrm{~h}$. It was poured into a preheated mold and cured.

For the preparation of epoxy/clay/CTBN nanocomposites, similar procedure was adopted for the mixing of nanoclay in epoxy as described in the preparation of epoxy/clay nanocomposite. After degassing step, 10-20 phr CTBN was added to the mixture by hand mixing for $10 \mathrm{~min}$. This is poured into a preheated mold and cured. All the above-described mixtures were cured in an oven according to the following cure cycle: (i) $120^{\circ} \mathrm{C}$ for $1 \mathrm{~h}$, (ii) $150^{\circ} \mathrm{C}$ for $1 \mathrm{~h}$, and (iii) $180^{\circ} \mathrm{C}$ for $2 \mathrm{~h}$.

\section{CHARACTERIZATION}

The fracture surface of the epoxy/CTBN blends and epoxy/clay/CTBN nanocomposites was examined to understand their detailed phase morphology. The cryogenic fracture surfaces of the samples were analyzed by using a scanning electron microscope (JEOL JSM 6390, JEOL India Private Limited, New Delhi, India) after platinum coating. SEM micrographs were obtained under conventional secondary electron imaging conditions with an accelerating voltage of $10 \mathrm{kV}$.

Dynamic DSC scans were performed using a TA Q200 instrument (TA Instruments, New Castle, DE, USA) to find out the glass transition temperature $\left(T_{\mathrm{g}}\right)$ of epoxy/CTBN blends and epoxy/clay/CTBN nanocomposites. The instrument was calibrated using an indium standard (weight $6.08 \mathrm{mg}$ ). A sample containing about $7-10 \mathrm{mg}$ of mixture was placed in an aluminum Hermetic DSC pan. The samples were heated dynamically from 0 to $250^{\circ} \mathrm{C}$ at a scanning rate of $10^{\circ} \mathrm{C}$.

To carry out the solvent uptake studies, cured samples of dimension $10 \mathrm{~mm} \times 15 \mathrm{~mm} \times 2 \mathrm{~mm}$ were used. The dimensions were maintained identical for all samples by edges ground with $\mathrm{SiC}$ paper using water as a lubricant and accurately measured with a caliper. All samples were dried to constant weight at room temperature in the presence of dry silica gel. The samples were immersed in acetone in an airtight container.

The weight of the samples was determined at suitable intervals by using an electronic microbalance with an accuracy of $0.001 \mathrm{~g}$. The samples were carefully taken from the solvent using forceps and wiped with lint-free tissue paper. The time required 

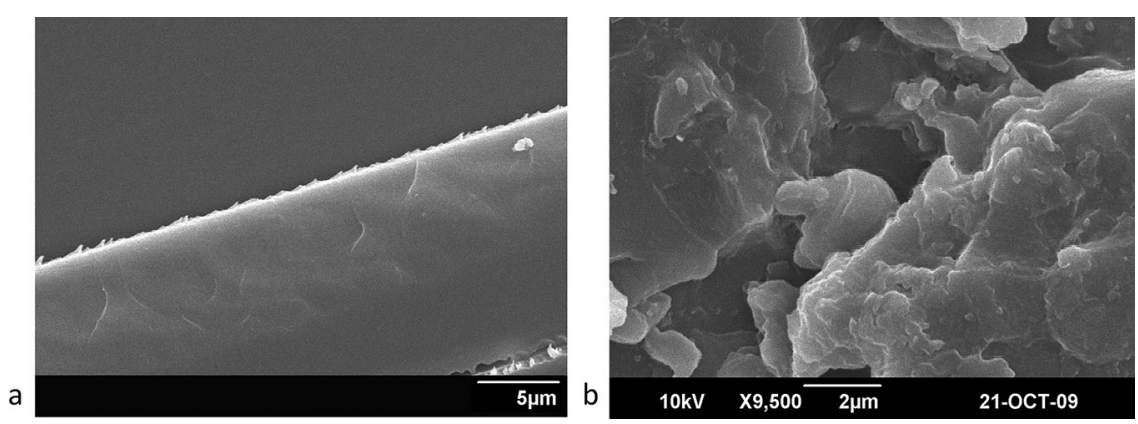

FIGURE 1. SEM images of (a) epoxy and (b) epoxy/3 phr clay nanocomposite.

for the weighing of the samples was considered sufficiently short for avoiding solvent evaporation or absorption. The experiment was repeated for five different batches of the samples; the accuracy of the weight measurements was supported by the fact that no noticeable scatter in the weight data curves was noted. The results of the solvent uptake experiments were expressed as $M_{t}$ function of time $\left(t^{1 / 2}\right)$, where $M_{t}$ is defined as follows:

$$
M_{t}(\%)=\frac{\left(w_{t}-w_{0}\right)}{w_{0}} \times 100
$$

where $W_{t}$ is the weight of the sample at time $t$ and $W_{0}$ is the Initial weight of the sample.

The acetone uptake in the samples can be modeled considering a Fickian behavior; therefore, for short immersion time, the following formula has been used ${ }^{16,20}$ :

$$
\frac{M_{t}}{M_{s}}=4\left(\frac{D t}{\pi h^{2}}\right)^{1 / 2}
$$

where $M_{t}$ is the acetone content at time $t, M_{s}$ is the equilibrium acetone content, $D$ is the diffusion coefficient, and $h$ is the sample thickness. Therefore, the diffusion coefficient $(D)$ can be determined from the initial slope of the solvent absorption curve versus the square root of time.

\section{Results and Discussion}

Figure 1 shows of the SEM images of the fracture surfaces of both epoxy and epoxy/3 phr clay nanocomposites. The fracture surface of the epoxy is smooth, which indicates the easy way of fracture to propagate in the matrix. However, the rough surface of the epoxy/3 phr clay nanocomposites indicates that the dispersed clay layers created an interruption to the fracture propagation. The SEM images of the fracture surfaces of epoxy/CTBN and epoxy/clay/CTBN with varying amounts of CTBN (Fig. 2) were carefully investigated. The epoxy/CTBN blends (Figs. 2a-2c) have two phase microstructure where the CTBN phase is dispersed in continuous epoxy matrix. As previously reported, the CTBN phase was separated from the hard epoxy matrix during the early stage of cure. ${ }^{21}$ As the CTBN content increases, the extent of phase separation increases and particle distribution become denser. The interparticle distance decreases with increasing CTBN content and will progress up to show a co-continuous morphology after $20 \mathrm{phr}$. The fracture surfaces of the epoxy/clay/CTBN nanocomposites (Figs. 2d-2f) show considerable roughness, indicating the fine dispersion of nanoclay along with the phase-separated CTBN particles. The domain size of the CTBN in epoxy/clay/CTBN nanocomposites is smaller than the corresponding values in epoxy/CTBN blend. ${ }^{21,22}$ The $\mathrm{X}$-ray diffraction was reported in our previous work to describe the structure of nanoclay in epoxy/clay/CTBN nanocomposite as a function of CTBN content. ${ }^{22}$ It was found that the $d$ spacing increased with an increase in CTBN content due to increase in the extent of intercalation of clay platelets by the penetration of low molecular weight CTBN into the clay galleries.

The $T_{\mathrm{g}}$ of the samples was calculated using dynamic DSC analysis. The heat flow versus temperature curves for epoxy/CTBN blends and epoxy/clay/CTBN nanocomposites are shown in Fig. 3, and the $T_{\mathrm{g}}$ values extrapolated from the graph are given in Table I. It is found that as the CTBN content increases the $T_{\mathrm{g}}$ of the epoxy get reduced. The lowering of $T_{\mathrm{g}}$ is due to the dissolution of rubber in the epoxy phase and is increased with an increase in rubber content. ${ }^{23}$ The lowest $T_{\mathrm{g}}$ value is shown by a blend containing $15 \mathrm{phr}$ CTBN; after this critical composition, the miscibility of the system reduces and for the blend containing $20 \mathrm{phr}$ the $T_{\mathrm{g}}$ starts to rise. The $T_{\mathrm{g}}$ of epoxy/3 phr clay nanocomposite is $\sim 12^{\circ} \mathrm{C}$ higher than neat epoxy, and this increase in $T_{\mathrm{g}}$ is attributed to the immobilization of the epoxy network by the intercalated clay layers. Moreover, the incorporation of nanoclay improved the $T_{\mathrm{g}}$ of the epoxy/CTBN blends and the $T_{\mathrm{g}}$ values of epoxy/clay/CTBN nanocomposite are much higher than that of neat epoxy. Among epoxy/clay/CTBN nanocomposites, the lowest $T_{\mathrm{g}}$ is achieved by a nanocomposite containing $15 \mathrm{phr}$ CTBN. The effect of CTBN content on $T_{\mathrm{g}}$ of epoxy/clay/CTBN nanocomposites is found to be similar to that in epoxy/CTBN blend.

Diffusion characteristics of acetone in neat epoxy, epoxy/ CTBN blends, epoxy/clay nanocomposite, and epoxy/clay/ CTBN nanocomposites were analyzed: The results of acetone uptake (percentage of the sample mass gain vs. square root of immersion time) for neat epoxy and epoxy/CTBN blends are shown in Fig. 4. It is clear from the plot that as the rubber content increases from 10 to $20 \mathrm{phr}$ the diffusion rate of acetone is increased. ${ }^{23}$

The acetone uptake curves for neat epoxy, epoxy/3 phr clay nanocomposite, and epoxy/clay/CTBN nanocomposites are shown in Fig. 5. It is clear from the curves that the presence of nanoclay, as expected, decreases the acetone uptake in 


\section{RESEARCH ARTICLE}
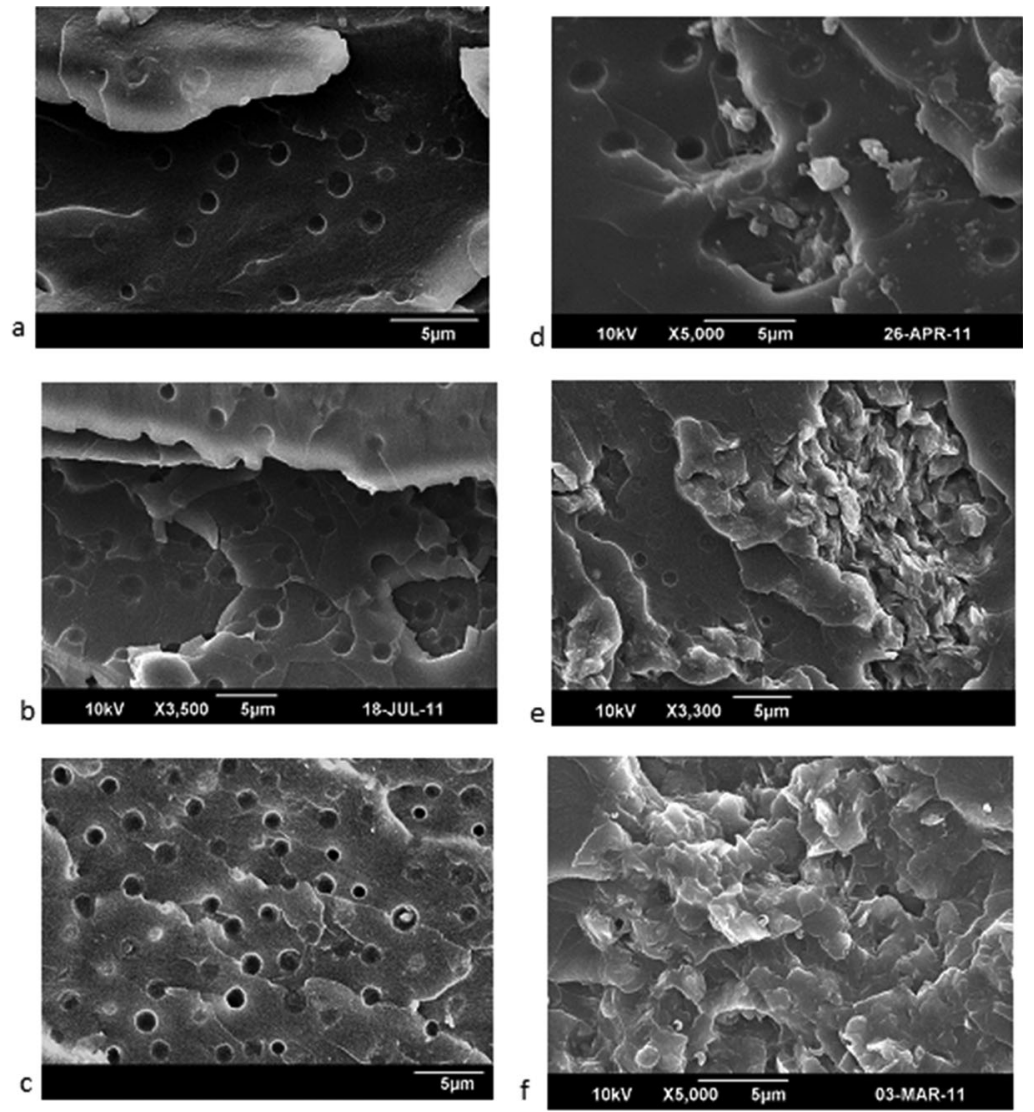

FIGURE 2. SEM images of epoxy/CTBN blend with (a) $10 \mathrm{phr}$ CTBN, (b) $15 \mathrm{phr}$ CTBN, and (c) $20 \mathrm{phr}$ CTBN and epoxy/3 phr clay/CTBN nanocomposites with (e) 10 phr CTBN, (f) 15 phr CTBN, and (g) 20 phr CTBN.
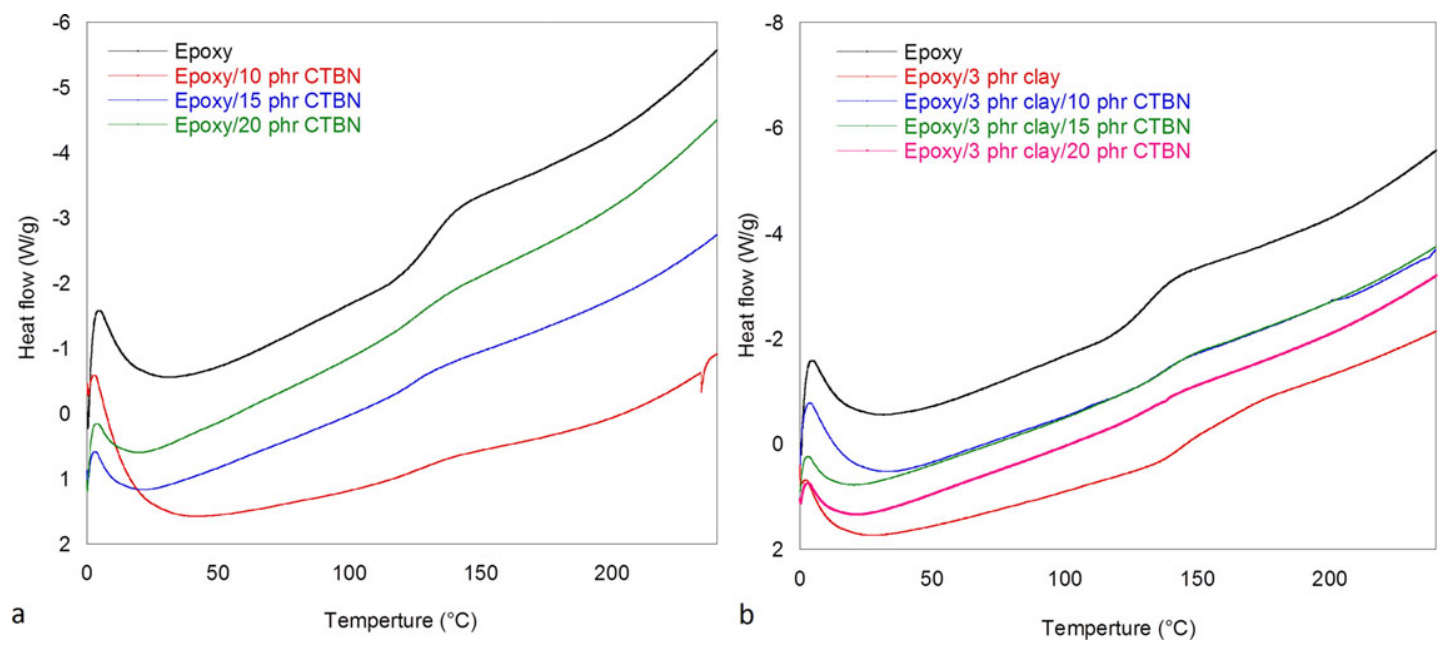

FIGURE 3. DSC heat flow versus temperature curves for (a) epoxy/CTBN blends and (b) epoxy/clay/CTBN nanocomposites as a function of CTBN content.

the epoxy, since the epoxy/clay nanocomposite systems show a reduced constant value of weight gain with respect of neat epoxy. In addition, the increase in CTBN content in epoxy/clay/CTBN, even if a final constant value was registered for all the samples containing increased content of liquid rubber, gives evidence of an increase in the diffusion rate. To have a compara- tive study of the diffusion behavior of epoxy/CTBN blend and epoxy/clay/CTBN nanocomposites, the diffusion coefficient of each sample was determined using Eq. (3):

$$
D=\pi\left(\frac{h}{4 M_{s}}\right)^{2}\left(\frac{M_{t}}{\sqrt{t}}\right)^{2}
$$


TABLE I

$T_{\mathrm{g}}$ of the Samples Obtained From DSC Heat Flow versus Temperature Curves

\begin{tabular}{ll}
\hline Sample & $T_{\mathrm{g}}\left({ }^{\circ} \mathrm{C}\right)$ \\
\hline Neat epoxy & 131.85 \\
Epoxy/10Phr CTBN & 128.96 \\
Epoxy/15Phr CTBN & 124.95 \\
Epoxy/20 phr CTBN & 127.03 \\
Epoxy/3 phr clay & 143.89 \\
Epoxy/3 phr clay/10 phr CTBN & 138.32 \\
Epoxy/3 phr clay/15 phr CTBN & 135.24 \\
Epoxy/3 phr clay/20 phr CTBN & 139.03 \\
\hline
\end{tabular}

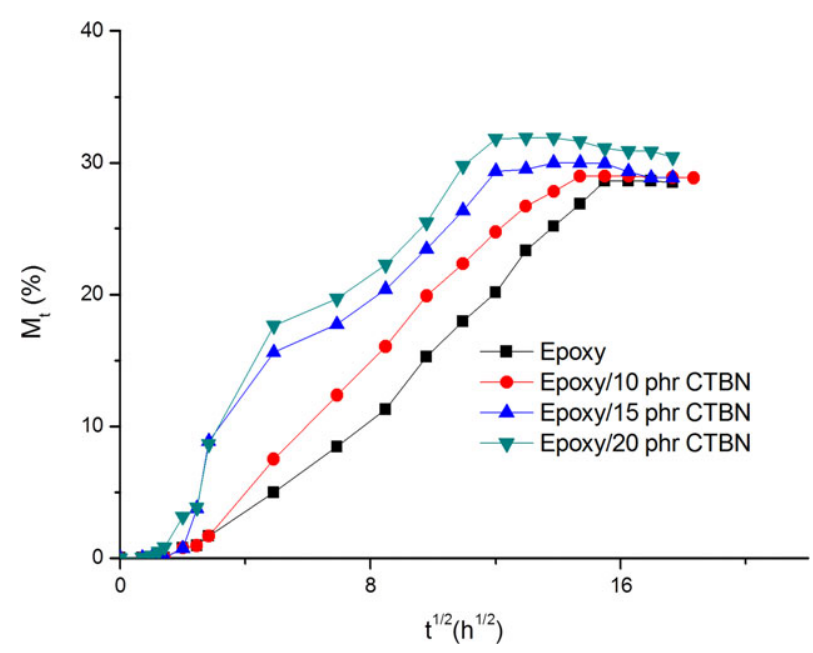

FIGURE 4. Acetone uptake profile for epoxy and epoxy/CTBN blends.

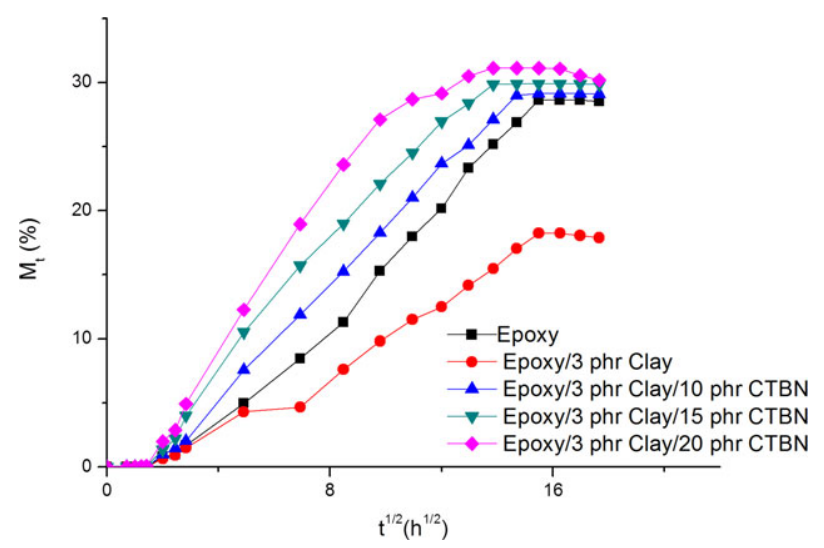

FIGURE 5. Solvent (acetone) uptake profile for epoxy/clay nanocomposite and epoxy/clay/CTBN nanocomposites.

The variation diffusion coefficient with CTBN content in epoxy/CTBN blend and epoxy/clay/CTBN nanocomposites is shown in Fig. 6. The increase in solvent uptake in the presence of CTBN can be explained considering both the ability of the highly polar acrylonitrile group to bind with acetone and the flexibilization of the matrix by the rubber phase. The liquid rubber makes the epoxy matrix flexible, with consequent easy diffusion of acetone through the matrix. The diffusion of solvent in the epoxy/CTBN blend is found to depend on CTBN

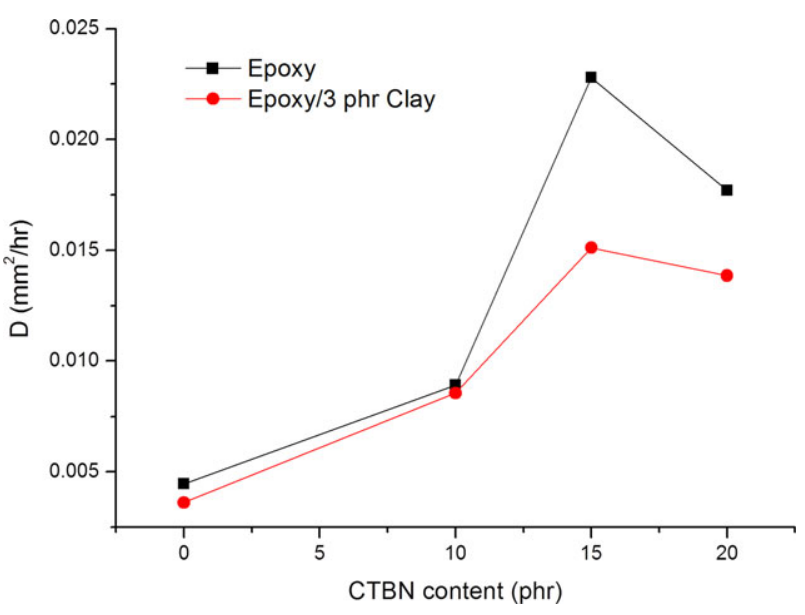

FIGURE 6. The diffusion coefficient for epoxy and epoxy/3 phr clay nanocomposite with varying CTBN content.

content of the blend, especially above $10 \mathrm{phr}$. It was observed that in the epoxy/CTBN blend, the diffusion coefficient initially increases with an increase in CTBN content, with a maximum value registered for the system containing $15 \mathrm{phr}$ of CTBN. With a further increase in CTBN, the diffusion coefficient was found to decrease. The variation of the diffusion coefficient with CTBN content can be related to the amount of dissolved rubber. As the amount of dissolved rubber increases, the matrix is flexiblized and the solvent diffuses more through the matrix. The diffusion coefficient of epoxy/CTBN blends fully agrees with the $T_{\mathrm{g}}$ values obtained from DSC. The diffusion of acetone in epoxy/CTBN blends is also related to the phase structure associated with each composition. At 20 phr CTBN content, the phase-separated domains become denser as seen in the SEM image of the surface of epoxy/20 phr CTBN blend (Fig. 2). The denser CTBN particles obstruct the easy diffusion of acetone through the matrix by creating a tortuous path.

As reported in Fig. 6, the diffusion coefficient of epoxy/CTBN blend decreases in the presence of $3 \mathrm{phr}$ nanoclay. The reduction in diffusion of acetone in the presence of clay is attributed to the tortuous path created by the clay platelets to solvent diffusion. As the aspect ratio of clay platelets is high, it will increase the tortuosity of the path of the solvent to pass through the matrix. Epoxy/clay/CTBN nanocomposites also show a similar trend in variation of the diffusion coefficient with CTBN content. The diffusion coefficient reaches a maximum for epoxy/clay/CTBN nanocomposite with 15 phr of CTBN and ultimately, it decreases for $20 \mathrm{phr}$ CTBN. In the case of epoxy/clay/CTBN nanocomposites also, the variation of the diffusion coefficient with CTBN content depends on both the amount of dissolved rubber in the epoxy phase and the phase morphology. The high acetone uptake in 15 and 20 phr CTBN-loaded system could be reduced dramatically by the incorporation of 3 phr nanoclay. Clay platelets, which we demonstrated to be located in epoxy phase and at the epoxy-CTBN interface, ${ }^{20,21}$ help to prevent the easy diffusion through the epoxy/clay/CTBN nanocomposites. Since the solvent diffusion in epoxy/CTBN blend and epoxy/clay/CTBN nanocomposites is partially related to the phase morphology associated with each CTBN composition, 


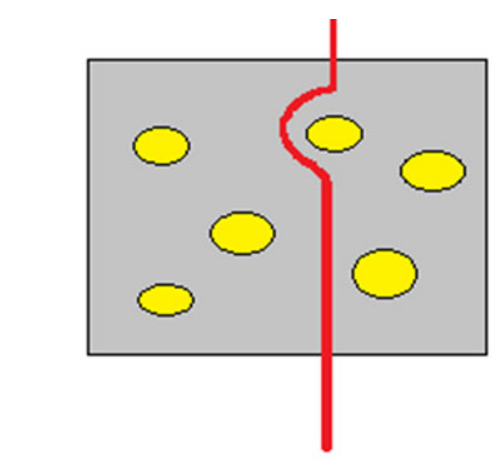

Epoxy/CTBN blend ( $=15 \mathrm{phr}$ CTBN)

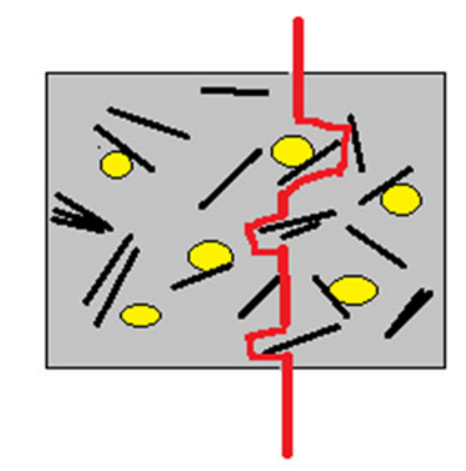

Epoxy/3 phr clay/CTBN nanocomposite

(=15 phr CTBN)

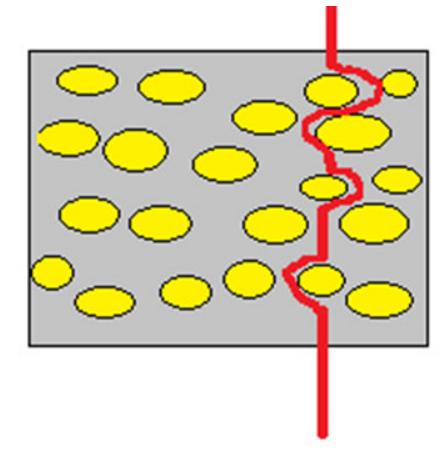

Epoxy/CTBN blend (>15 phr CTBN)

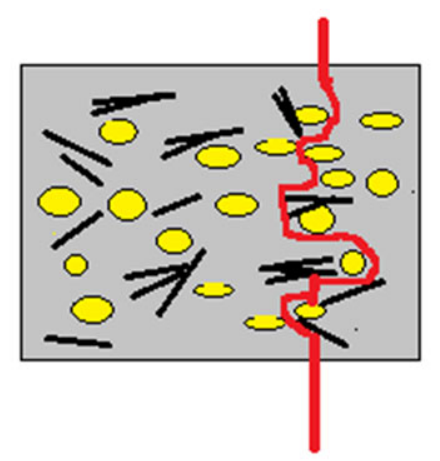

Epoxy $/ 3$ phr clay/CTBN nanocomposite ( $>15 \mathrm{phr}$ CTBN)

FIGURE 7. Schematic diagram showing the difference in the diffusion path of solvent in epoxy/CTBN blend and epoxy/clay/CTBN nanocomposites having different CTBN content.

we proposed a composition-dependent diffusion mechanism. The proposed diffusion mechanism is depicted in Fig. 7. In this model, the epoxy/CTBN blend having CTBN content higher than $15 \mathrm{phr}$ has a more tortuous path for the solvent diffusion when compared with blends having $15 \mathrm{phr}$ CTBN. The epoxy/clay/CTBN nanocomposites have the ability to create better tortuous paths, due to the presence of the high aspect ratio clay platelets, than the epoxy/CTBN blends, irrespective of the composition. However, in epoxy/clay/CTBN nanocomposite with CTBN content higher than $15 \mathrm{phr}$, both the denser CTBN particles and clay platelets create more tortuous paths for the diffusion of acetone than in epoxy/clay/CTBN nanocomposites at 15 phr CTBN.

\section{Conclusions}

The main conclusions that can be found in the diffusion studies of acetone in epoxy/CTBN blends and epoxy/clay/CTBN nanocomposites are listed here.

- The diffusion of acetone in epoxy/CTBN blends and epoxy/clay/CTBN nanocomposites is a function of both dissolved rubber in the epoxy phase and the phase structure associated with each composition.

- The high acetone uptake in 15 and 20 phr CTBN-loaded epoxy/CTBN blends, dramatically reduced by the incorporation of 3 phr nanoclay. Both the clay platelets, which are located in epoxy phase and at the epoxy-CTBN interface, help to prevent the easy diffusion through the epoxy/clay/CTBN nanocomposites.

Finally, a composition-dependent diffusion mechanism has been suggested for epoxy/CTBN blends and epoxy/clay/CTBN nanocomposites. Owing to the presence of the high aspect ratio clay platelets, the diffusion of acetone undergoes more tortuous path in epoxy/clay/CTBN nanocomposites than in epoxy/CTBN blends irrespective of the composition. In epoxy/clay/CTBN nanocomposite with CTBN content higher than $15 \mathrm{phr}$, both the denser CTBN particles and clay platelets create more tortuous paths for the diffusion of acetone than in epoxy/clay/CTBN nanocomposites at 15 phr CTBN. Since the application of liquid rubber toughened epoxy are mostly in aerospace/automotive industry as adhesives and sealants, where they are highly prone to contact with organic solvents frequently, the development of rubber-toughened epoxy/clay nanocomposites with dramatically reduced solvent uptake properties will greatly extend their potential in the area. 


\section{Acknowledgments}

The authors would like to thank Huntsmann for their kind supply of chemicals for the study.

\section{References}

1. Di Pasquale, G.; Motta, O.; Recca, A.; Carter, J. T.; McGrail, P. T.; Acierno, D Polymer 1997, 38, 4345.

2. Pearson, R. A.; Yee, A. F. Polymer 1993, 34, 3658.

3. Ratna, D.; Banthia, A. K. Macromol Res 2004,12, 11

4. Saadati, P.; Baharvand, H.; Rahimi, A.; Morshedian, J. Iran Polym J 2005,14, 637.

5. Wang, K.; Chen, L.; Wu, J.; Toh, M. L.; He, C.; Yee, A. F. Macromolecules 2005 $38,788$.

6. Pluart, L. L.; Duchet, J.; Sautereau, H. Polymer 2005, 46, 12267.

7. Zheng, Y.; Chonung, K.; Wang, G.; Wei, P.; Jiang, P. J Appl Polym Sci 2009, 111, 917.
8. Johnsen, B. B.; Kinloch, A. J.; Mohammed, R. D.; Taylor, A. C.; Sprenger, S. Polymer 2007, 48, 530 .

9. Kaplan, M. L. Polym Eng Sci 1991, 31, 689.

10. Voo, R.; Mariatti, M.; Sim, L. C. Polym Adv Technol 2012, 23, 1620.

11. Prolongo, S. G.; Gude, M. R.; Ureña, A. Composites, Part A 2012, 43, 2169

12. Chen, C.; Khobai, M.; Curliss, D. Prog Org Coating 2003, 47, 376.

13. Liu, W.; Hoa, S. V.; Pugh, M. Compos Sci Technol 2005, 65, 2364.

14. Abacha, N.; Kubouchi, M.; Sakai, T.; Tsuda, K. J Appl Polym Sci 2009, 112, 1021.

15. Mohan, T. P.; Kanny, K. Composites, Part A 2011, 42, 385.

16. Alamri, H.; Low, I. M. Composites, Part A 2013, 44, 23.

17. Bascom, W. D.; Cottington, R. L.; Jones, R. L.; Peyser, P. J Appl Polym Sci 1975, 19, 2545.

18. Kang, B. U.; Jho, J. Y.; Kim, J.; Lee, S.-S.; Park, M.; Lim, S.; Choe, C. R. J Appl Polym Sci 2001,79, 38.

19. Thomas, R.; Abraham, J.; Thomas, S. P.; Thomas, S. J Polym Sci, Part B: Polym Phys 2004, 42, 2531.

20. Alamri, H.; Low, I. M. Polym Test 2012, 31, 620.

21. Vijayan, P. P.; Puglia, D.; Maria, H. J.; Kenny, J. M.; Thomas, S. RSC Adv 2013 3, 24634

22. Vijayan, P. P.; Puglia, D.; Kenny, J. M.; Thomas, S. Soft Matter 2013, 9, 2899

23. Tripathi, G.; Srivastava, D. Mater Sci Eng A 2007, 443, 262.

24. McEwan I.; Pethrick, R. A.; Shaw S. J. Polymer 1999, 40, 4213. 